\title{
The Effect of Diethylstilbestrol on the Susceptibility of Rats to Hematogenous Pyelonephritis *
}

\author{
Vincent T. Andriole and George L. Cohn \\ (From the Department of Medicine, Yale University School of Medicine, \\ New Haven, Conn.)
}

Renal infection rarely occurs after the intravenous injection of gram-negative bacteria, namely, Escherichia coli into normal animals (1). If the kidney is subjected to experimental trauma (2), ureteral ligation (3), medullary scarring secondary to cautery injury (4), or chemical injury (1), an increased susceptibility to infection results.

These experimental models, however, do not explain the high indidence of pyelonephritis in human pregnancy (5-12). The development of pyelonephritis in pregnant women has been ascribed to the anatomical and functional changes of the urinary tract usually observed from the third month of pregnancy to a few weeks after delivery $(5,7$, 12). Dilatation of the ureters and renal pelves has been attributed to obstruction of the ureter by the pregnant uterus (13), hypertrophy of the longitudinal sheath of muscle bundles at the lower end of the ureter (6), or hormonal "imbalance" producing atony of the ureter with resultant diminished peristaltic activity (14). Sinee human f $\mathrm{t}=$ males have an exaggerated production of estrogens during pregnancy (15), it seemed desirable to investigate this possible relationship in animals. The results indicate that diethylstilbestrol ${ }^{1}$ administration produces varying degrees of hydronephrosis and an increased susceptibility of the rat kidney to coliform infection.

\section{Methods}

Animals. White male and female Sprague-Dawley strain rats, weighing 150 to 250 and 125 to $145 \mathrm{~g}$, respectively, were used. Animals were weighed on the first and last day of each experiment. All animals were fed Purina lab chow pellets and tap water ad libitum.

* Eivhmitter for publication Deremher 1.3, 1963; acsepted February 6, 1964.

These studies were supported by U. S. Public Health Service grants EF 13,401, E 1850, A-4222, and A-254.

1 The chemical formula of diethylstilbestrol, abbreviated DES, is $4,4^{\prime}$-dihydroxy- $\alpha, \beta$-diethylstilbene.
Diethylstilbestrol. ${ }^{2}$ Pellets contained $75 \%$ diethylstilbestrol and $25 \%$ cholesterol by weight. The pellets were weighed ${ }^{3}$ and placed subcutaneously through a skin incision, $15 \mathrm{~mm}$ long, at the base of the neck of rats under light ether anesthesia. The incision was closed with a skin clip. At the time of sacrifice, the pellets were recovered from most animals, dried, and weighed. The amount of diethylstilbestrol absorbed was estimated to be 0.75 times the difference in pellet weight. Shamnperntinn was carried out in control rats.

Bacteria. The strain of $(2$ coli (FCY 9) usel has been maintained in this laboratory for 7 years, and details of its handling were described previously (3). A volume of $0.5 \mathrm{ml}$ of a 4-hour culture (containing 2.5 to $7.5 \times 10^{8}$ organisms per $\mathrm{ml}$ ) was injected into the tail vein of each rat. Tenfold dilutions in $0.85 \%$ sodium chloride solution were incubated in agar pour plates to enumerate each inoculum.

Removal of the urinary tract for bacteriological and pathological studies. Sterile technique was maintained during all surgical procedures. Under pentobarbital anesthesia, the abdominal wall was cleaned with $70 \%$ alcohol and incised so that the entire urinary tract was exposed. After urine and blood were collected in some äiiiiiäls, thie kidneys, ufeters, and bladder were renuved and placed in Petri dishes for macroscopic examination and sectioning. A mid-line longitudinal section was made in each kidney which appeared grossly abscessed or hydronephrotic. One-half of the kidney, both ureters, and the bladder were fixed in $10 \%$ formol for histological examination. The remaining half of the kidney was placed in a Teflon tissue homogenizer and ground in 4.5 $\mathrm{ml}$ of $0.85 \%$ sodium chloride solution until a homogeneous suspension was obtained. Whole kidneys were cultured after homogenization with $9.0 \mathrm{ml}$ of saline. These concentrations represented a $10^{-1}$ dilution. Subsequent tenfold dilutions were prepared in saline solution. Agar pour plates were made from these dilutions, and colony counts were determined after incubation for 48 hours. Counts ranging between 30 and 300 colonies were taken as most nearly representative. When the greatest dilution contained too many colonies to be counted, the num-

\footnotetext{
2Diethylstilbestrol peliets were kindiy supplied by ỉr. William U. Gardner, Department of Anatomy, Yale University School of Medicine.

${ }^{3}$ Sartorius-Werke balance, model DP $2 / 200$ g, Gottingen, Germany.
} 
ber was recorded as greater than 1,000. The identification of $E$. coli was confirmed by subculturing some colonies in desoxycholate, Kliger's iron, and Simmons citrate agar. ${ }^{4}$

Urine culture. Immediately after opening the abdominal cavity a small quantity of urine was aspirated through the bladder wall. One loopful of this was streaked on blood and desoxycholate agar. In certain animals serial dilutions of urine were made in nutrient broth, and pour plates were made for final bacteriological count. Organisms present in the plates were identified as described previously.

Blood culture. Blood cultures were taken by direct heart puncture. Pour plates containing $0.1 \mathrm{ml}$ of blood were incubated for 48 hours, and the number of colonies was recorded. Bacterial growth was identified as already described.

Criteria of infection. Kidneys were considered infected when they contained $5 \times 10^{4}$ or more colonies (3). Urine cultures were considered positive when 10 or more colonies were found on the streaked plate. This concentration is equivalent to $10^{3}$ to $10^{4}$ colonies per $\mathrm{ml}$ of urine. Blood cultures were considered positive when E. coli was found in the blood agar pour plates.

Intravenous pyelograms. After induction of anesthesia with pentobarbital sodium, $2.0 \mathrm{ml}$ of a $50 \%$ solution of sodium 3,5-diacetamido-2,4,6-triiodobenzoate ${ }^{5}$ was injected into the lateral tail vein of the rat. Pyelograms were obtained 20 to 25 minutes after injection, with 2 times X-ray magnification, an ultrafine focal spot tube, ${ }^{6}$ and 47 kilovoltage peak (three phase).

\section{Results}

I. The effect of diethylstilbestrol on susceptibility of female rat kidneys to infection ${ }^{7}$

Diethylstilbestrol pellets were implanted subcutaneously in 24 female rats. An additional 24 animals were sham-operated on. Forty-nine days later each rat was inoculated with the bacterial culture. Approximately equal numbers of diethylstilbestrol-treated and sham-prepared animals were sacrificed eight (group I), 12 (group II), 21 (group III), and 28 (group IV) days after bacterial inoculation (Table I). The urinary tracts

4 Difco Laboratories, Detroit, Mich.

5 Hypaque, Winthrop Laboratories, New York, N. Y.

${ }^{6}$ Biangulex Rapidex Tube- $-0.26 \mathrm{~mm}$ focal spot, designed and constructed by Siemens-Reiniger-Werke, Erlaugen, Germany.

7 This series of experiments was a pilot study. To insure a state of "hyperestrogenism," the rats were treated with DES for 49 days before inoculation with coliform bacilli. The results of this study determined our experimental protocol with the male rats (Results, II). were then studied as already described. In addition, the ovaries were removed and examined histologically for verification of diethylstilbestrol effect.

Table I lists the colony count per kidney in each group. Six of the 12 kidneys in estrogentreated animals in group I, and 4 of 12 kidneys in group II were infected. No infections were observed in sham-operated animals of groups I and II. Two of 16 kidneys in treated rats in group III were infected. One kidney in the sham-operated group III animals was infected. One of eight kidneys in treated rats in group IV was infected. No infection was observed in the shamoperated animals in group IV.

Pyelograms were obtained on most animals in group III and IV. Five of eight diethylstilbestroltreated animals in group III showed bilateral hydronephrosis. One diethylstilbestrol-treated animal in group IV showed hydronephrosis on the

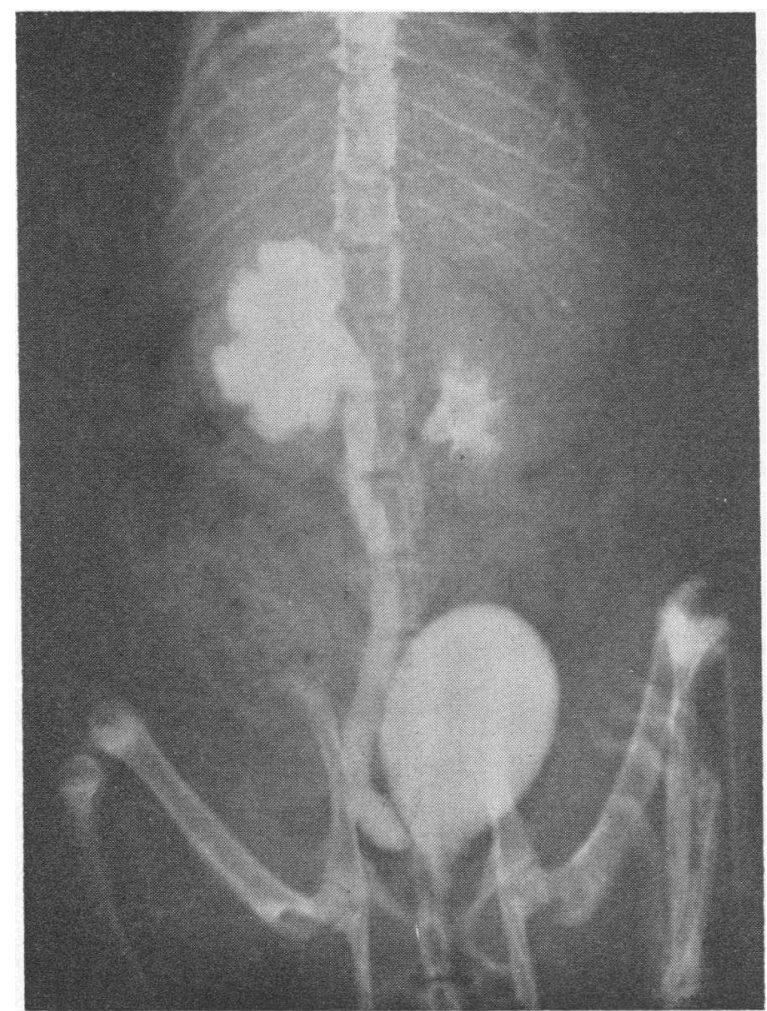

Fig. 1. Intravenous pyelogram of female rat (GROUP IV) AFTER 77 DAYS OF DIETHYLSTILBESTROL TREATMENT, SHOWING HYDRONEPHROSIS OF RIGHT KIDNEY AND URETER. 


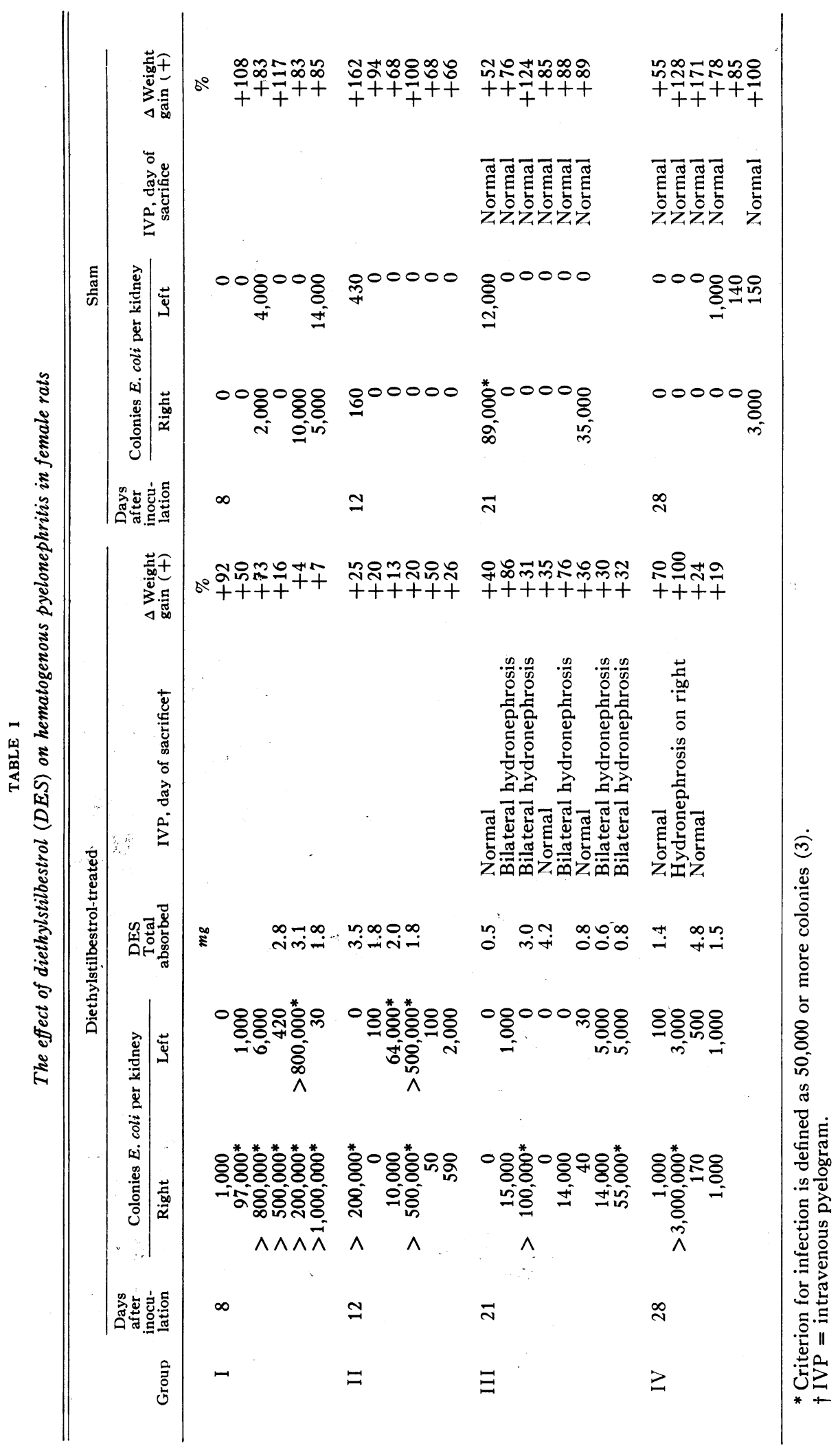




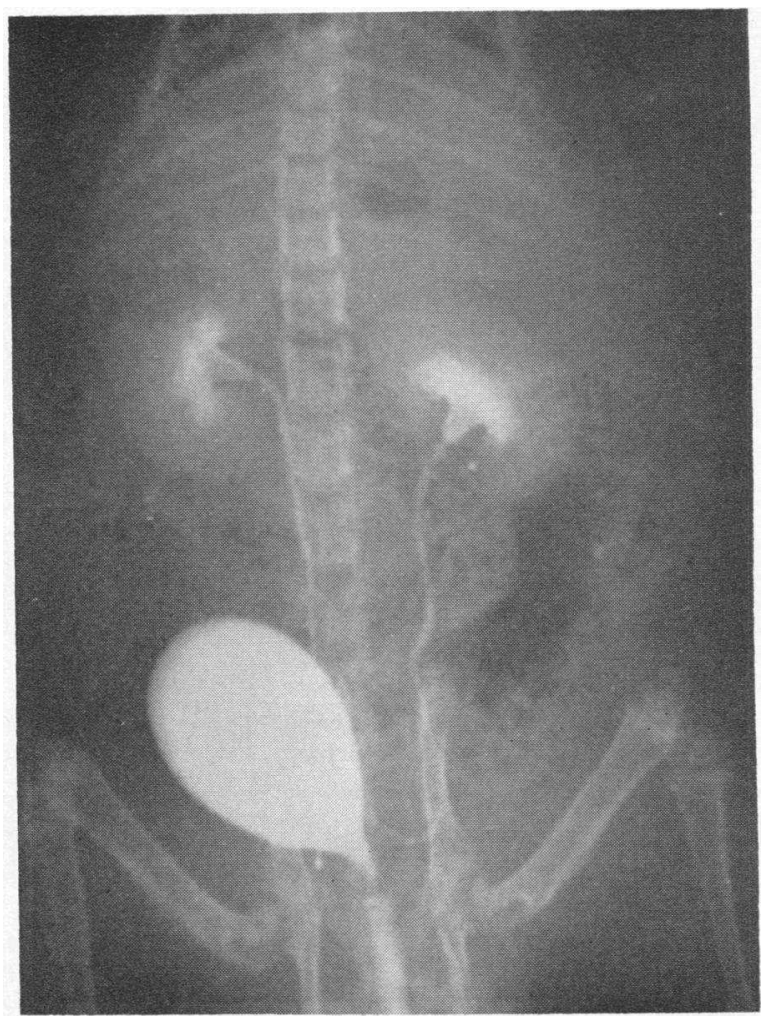

Fig. 2. Normal intravenous pyelogram of ShamOPERATED FEMALE RAT.

right (Figure 1). Pyelograms in sham animals in groups III and IV were normal (Figure 2).

Histologically, the ovaries of diethylstilbestroltreated rats were atrophic. Ovaries of shamoperated animals were normal.
Body weight of sham-operated and diethylstilbestrol-treated female rats. Sham-operated female rats increased their body weight $94 \%$ (mean) above the body weight at the beginning of the study. Diethylstilbestrol-treated rats increased their body weight $42 \%$ (mean) above the body weight at the beginning of the experiment. No diethylstilbestrol-treated rat lost weight during the study (Table I).

II. The effect of diethylstilbestrol on susceptibility of male rat kidneys to infection

Normal urinary tracts were observed by pyelography in 48 male rats (Figure 3). Diethylstilbestrol pellets were implanted subcutaneously in 24 , and the remaining 24 animals were shamoperated on. The animals were then divided into four groups, each group containing six diethylstilbestrol-treated and six sham-operated animals.

Group I received the bacterial inoculum on day 1 of estrogen administration, and pyelograms were obtained on day 8. Animals were sacrificed, and kidneys were removed, homogenized, and quantitatively cultured. No infection was observed in kidneys of diethylstilbestrol-treated or sham-operated animals (Table II). Pyelography revealed hydronephrosis on the left in one diethylstilbestroltreated animal. Pyelograms were normal in the sham-operated animals.

Group II received the infectious challenge on day 8 after estrogen administration or sham-opera-

TABLE II

The effect of 8 days of diethylstilbestrol treatment and the development of pyelonephritis. Group I: Challenged on day 1 of estrogens

\begin{tabular}{|c|c|c|c|c|c|c|c|c|c|}
\hline & \multicolumn{2}{|c|}{ Colonies E. coli } & \multirow[b]{2}{*}{$\begin{array}{c}\text { Gross } \\
\text { abscesses }\end{array}$} & \multirow[b]{2}{*}{$\begin{array}{l}\text { Urine } \\
\text { culture }\end{array}$} & \multirow[b]{2}{*}{$\begin{array}{l}\text { Blood } \\
\text { culture }\end{array}$} & \multirow{2}{*}{$\begin{array}{c}\text { Gross } \\
\text { hydrone- } \\
\text { phrosis }\end{array}$} & \multirow[b]{2}{*}{$\begin{array}{l}\text { IVP, day of } \\
\text { sacrifice }\end{array}$} & \multirow{2}{*}{$\begin{array}{c}\text { DES } \\
\text { Total } \\
\text { absorbed }\end{array}$} & \multirow[b]{2}{*}{$\underset{\text { gain }}{\Delta \text { Weight }}$} \\
\hline & $\begin{array}{l}\text { Right } \\
\text { kidney }\end{array}$ & $\begin{array}{c}\text { Left } \\
\text { kidney }\end{array}$ & & & & & & & \\
\hline & & & & & & & & $m g$ & $\%$ \\
\hline DES- & 29,000 & 15,000 & $\mathbf{0}$ & $\mathbf{0}$ & $\mathbf{0}$ & $\mathbf{0}$ & Normal & 0.38 & +6 \\
\hline \multirow[t]{5}{*}{ treated } & 29,000 & 10,000 & $\mathbf{0}$ & $\mathbf{0}$ & & 0 & Normal & 0.23 & +26 \\
\hline & 210 & 3,000 & $\mathbf{0}$ & & $\mathbf{0}$ & $\mathbf{0}$ & Normal & 0.60 & +6 \\
\hline & 130 & 2,000 & $\mathbf{0}$ & $\mathbf{0}$ & & 0 & Normal & 0.30 & +5 \\
\hline & 7,000 & 3,000 & $\mathbf{0}$ & $\mathbf{0}$ & $\mathbf{0}$ & $\mathbf{0}$ & Normal & 0.30 & +7 \\
\hline & 150 & 1,000 & $\mathbf{0}$ & 0 & $\mathbf{0}$ & 0 & Hydronephrosis, left & 0.23 & +7 \\
\hline \multirow[t]{6}{*}{ Sham } & 27,000 & 4,000 & $\mathbf{0}$ & & & $\mathbf{0}$ & Normal & & +6 \\
\hline & 15,000 & 14,000 & $\mathbf{0}$ & 0 & 0 & $\mathbf{0}$ & Normal & & +4 \\
\hline & $1 ; 000$ & 790 & $\mathbf{0}$ & 0 & $\mathbf{0}$ & $\mathbf{0}$ & Normal & & +9 \\
\hline & 370 & 4,500 & $\mathbf{0}$ & $\mathbf{0}$ & & $\mathbf{0}$ & Normal & & +23 \\
\hline & 25,000 & 5,000 & 0 & 0 & o & 0 & Normal & & +1 \\
\hline & 3,000 & 20,000 & 0 & 0 & 0 & & Normal & & +27 \\
\hline
\end{tabular}




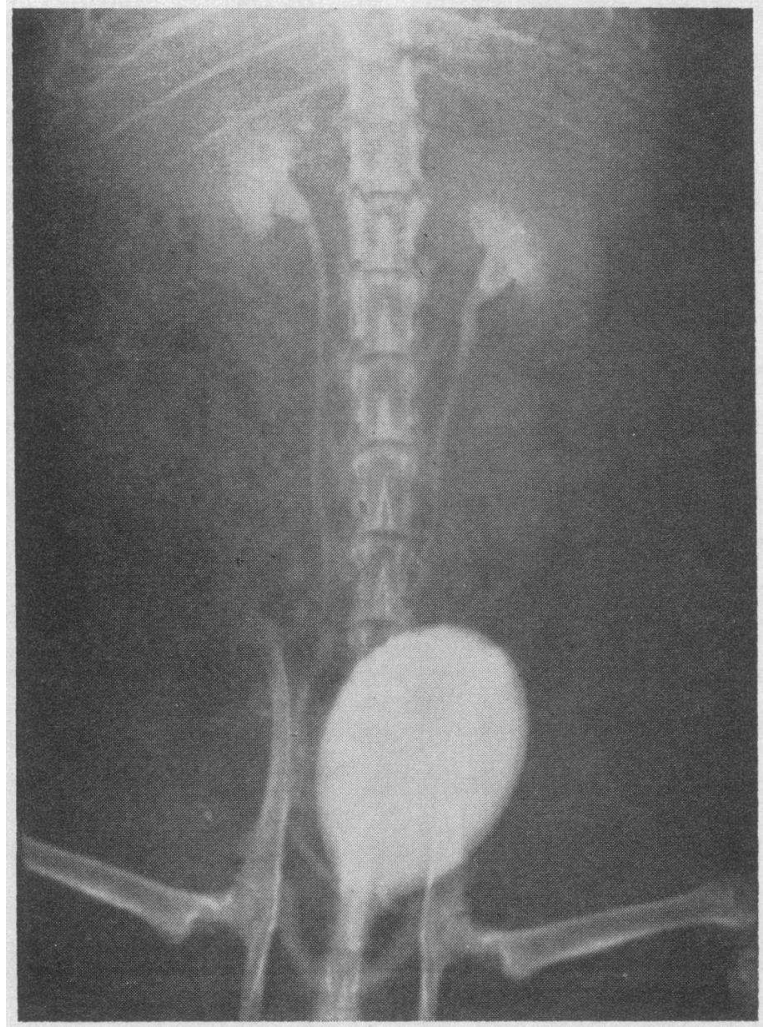

Fig. 3. Normal intravenous pyelogram of male rat BEFORE DIETHYLSTILBESTROL TREATMENT.

tion, and pyelograms were obtained 8 days after that. Six of 12 kidneys in treated rats were infected, compared with two of 12 kidneys in shamoperated animals (Table III). Gross abscesses were seen in four of the six diethylstilbestroltreated infected kidneys. One kidney from an animal in the treated group demonstrated a gross abscess and hydronephrosis but was sterile. ${ }^{8} \mathrm{Hy}$ dronephrosis was present on gross examination and on pyelography in three diethylstilbestroltreated animals. Pyelograms were normal in sham-operated animals (Table III).

Group III received the bacterial inoculation on day 14 after diethylstilbestrol administration or sham operation, and pyelograms were made 8 days after that. Eleven of 12 kidneys in treated rats were infected (Table IV). Gross abscesses were seen in 8 of 11 infected kidneys. Hydronephrosis was present either on gross examination or pyelography in all kidneys studied (Fig-

8 The abscessed area was not cultured, since this half of the kidney was removed for histologic examination. ure 4). One of 12 kidneys in a sham-operated animal was infected. Hydronephrosis was absent in the sham group on gross examination and pyelography.

Group IV received E. coli intravenously on day 21 after diethylstilbestrol administration or sham operation, and pyelograms were obtained 8 days after that. Five of 12 kidneys in treated rats were infected (Table V). Hydronephrosis was observed grossly or on pyelography in the four infected animals (Figure 5). Hydronephrosis was also present radiographically in two noninfected treated animals. Infection was present in one of 12 kidneys of the six sham-operated animals. Hydronephrosis was absent grossly, and pyelograms were normal in sham-operated animals ( $\mathrm{Ta}-$ ble V).

Body weights of sham and estrogen-treated male rats. Sham-operated male rats increased their body weight $30 \%$ (mean) above the weight at the beginning of the study compared to an increase of $6 \%$ (mean) observed in diethylstilbestrol-

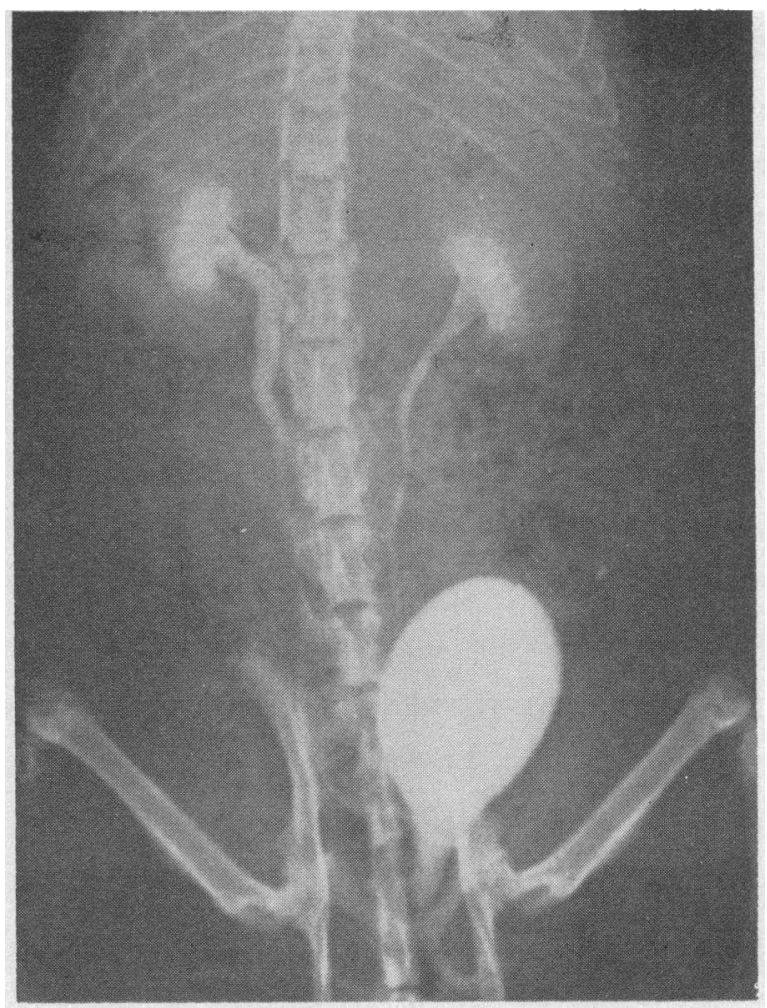

Fig. 4. Intravenous pyelogram of male rat (FigURE 3) AFTER 22 DAYS OF DIETHYLSTILBESTROL TREATMENT, SHOWING DEVELOPMENT OF HYDRONEPHROSIS ON RIGHT. 

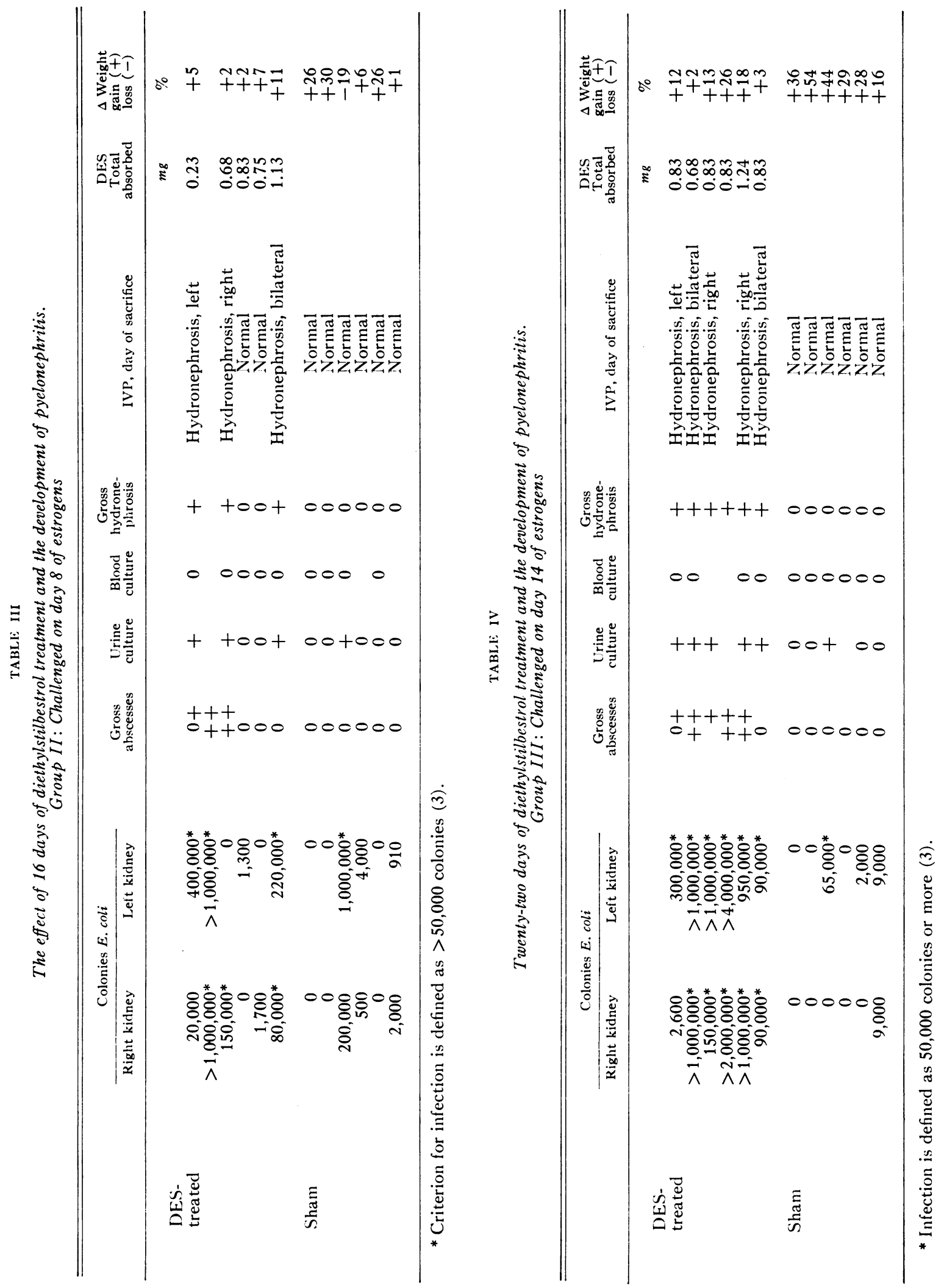


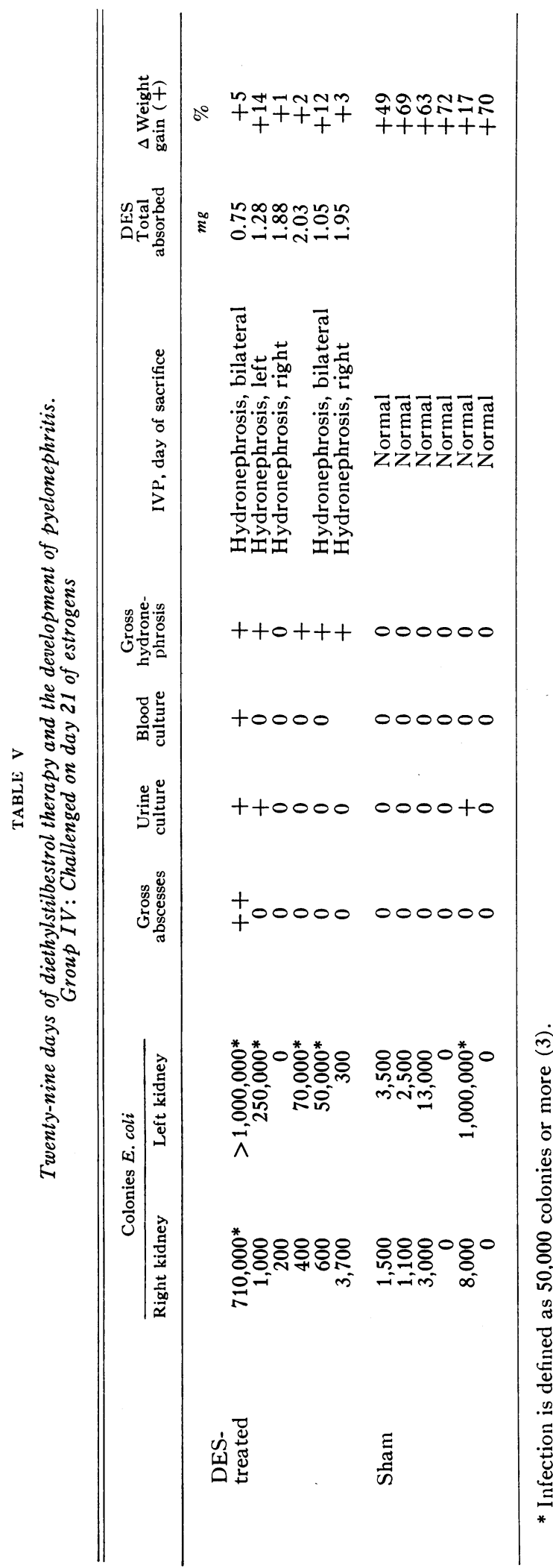

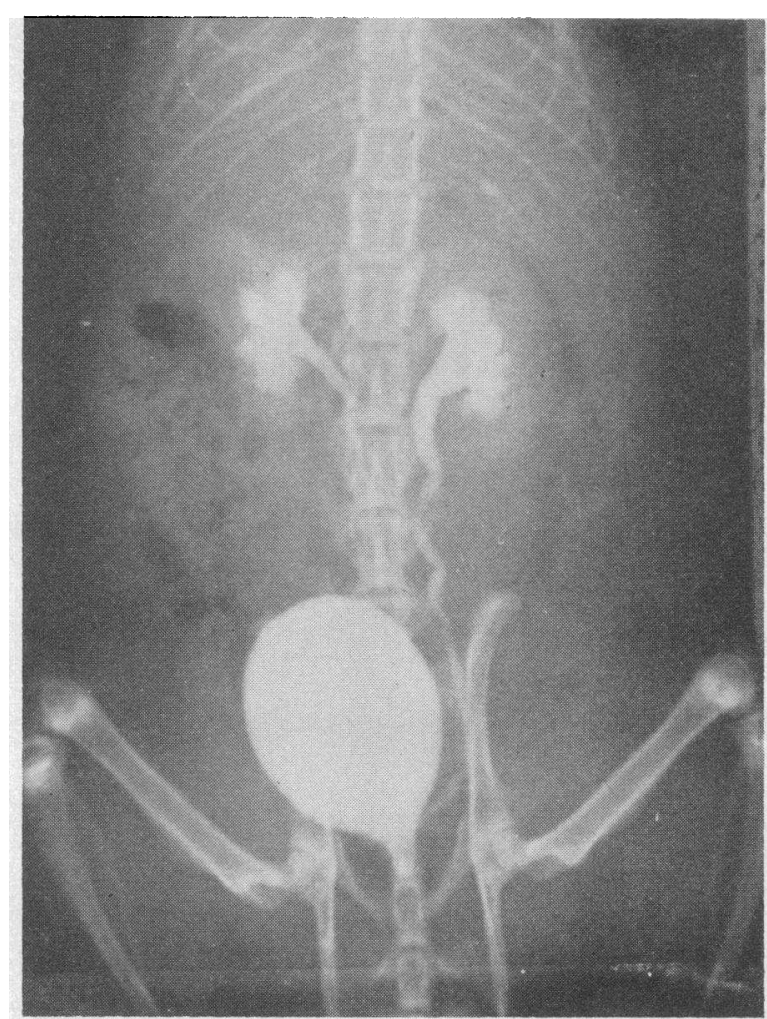

Fig. 5. Intravenous Pyelogram of MALE RAT AFter 29 DAYS OF DIETHYLSTILBESTROL TREATMENT, SHOWING DEVELOPMENT OF HYDRONEPHROSIS ON LEFT.

treated rats. No treated rat lost weight during the study (Tables II-V).

Pathology of sham-operated and estrogentreated male rats. The kidneys, ureters, and bladders were grossly edematous in most treated rats in group III and IV. The bladder and distal ureters of treated rats in groups III and IV revealed squamous metaplasia of the transitional epithelium. The cytoplasm of some epithelial cells had a pale-staining appearance. Other cells appeared flattened with small dark-staining nuclei. Intercellular bridges were observed, and the epithelium ranged from three to six cells in thickness. These changes were more pronounced in the bladder. Similar changes were noted in the proximal ureters of diethylstilbestrol-treated rats in group IV. Microscopically the lower urinary tracts of diethylstilbestrol-treated rats in groups I and II and sham-operated animals in all groups were normal.

Renal infection in diethylstilbestrol and shamoperated animals was characterized by a collec- 


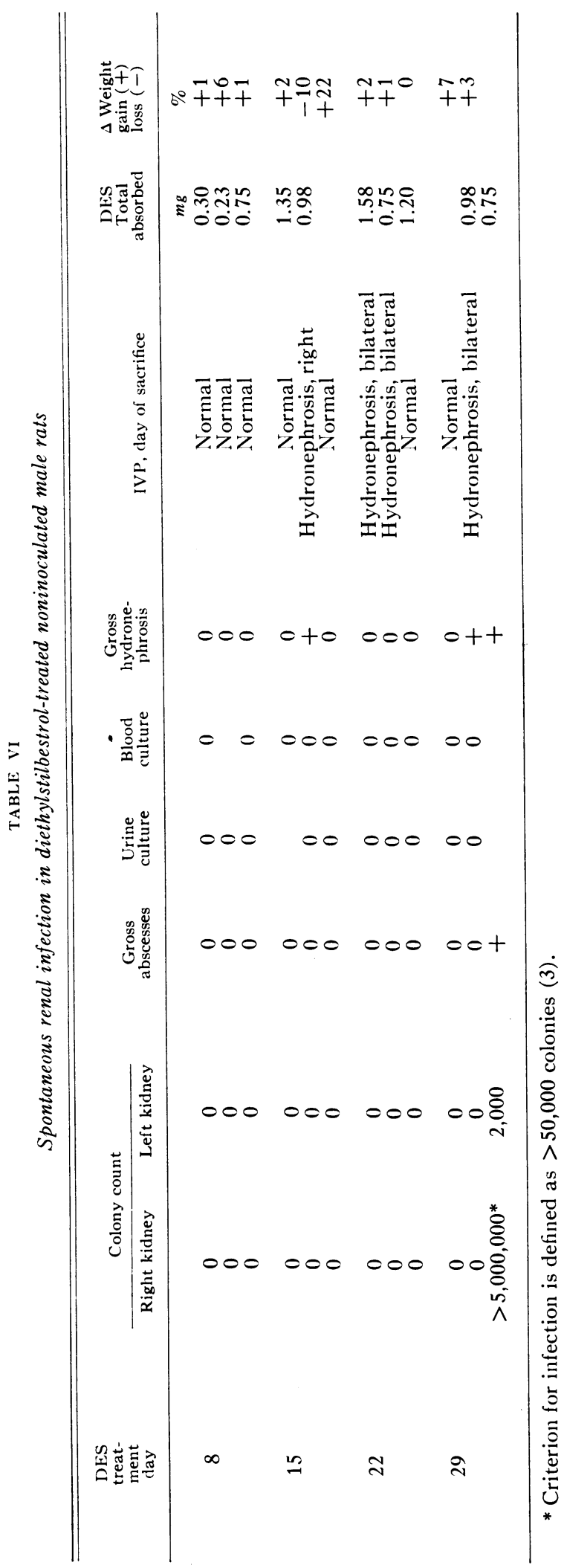

tion of small abscesses in a wedge-shaped area with the apex in the medulla and base in the cortex. Collections of polymorphonuclear leukocytic exudates were observed within and outside of the tubules and in the cortex. The area of involvement was sharply demarcated from the surrounding normal kidney. Colloid casts were sometimes seen in tubules surrounded by polymorphonuclear leukocytes.

The effect of diethylstilbestrol on spontaneous renal infection in male rats. Diethylstilbestrol tablets were implanted subcutaneously in 12 male rats with normal pyelograms. Animals in this group did not receive $E$. coli. Groups of three animals were sacrificed on days $8,15,22$, and 29 after estrogen administration. The kidneys were removed, homogenized, and cultured quantitatively. Pyelograms were obtained in each animal on the day of sacrifice. One kidney in an animal sacrificed 29 days after diethylstilbestrol treatment was infected (Table VI). The organism was identified as $E$. coli, but was not the same strain as used in the experiments. Gross hydronephrosis was present in one animal 15 days and in two animals 29 days after diethylstilbesterol treatment. Pyelograms revealed hydronephrosis in one animal sacrificed 15 days, two animals sacrificed 22 days, and one animal sacrificed 29 days after diethylstilbestrol treatment.

\section{Discussion}

The data indicate that rats treated with diethylstilbestrol develop hydronephrosis and an increased susceptibility to renal parenchymal infection associated with squamous metaplasia of the transitional epithelium of the bladder and distal and proximal ureters. The hematogenous inoculation of $E$. coli into the diethylstilbestrol-treated rats resulted in typical wedge-shaped abscesses in the kidneys. Parenchymal infection did not occur in diethylstilbestrol-treated male animals unless hydronephrosis was present.

Previous observations of Guze and Beeson (3) indicate that after ureteral ligation susceptibility of the rat kidney to infection is maximally enhanced at the time obstruction is produced and that this susceptibility decreases progressively as the interval between obstruction of the urinary tract and lodgement of the bacteria in the kidney 
is prolonged. The present studies support these observations. Susceptibility of the male rat kidney is greatest when the bacteria are inoculated 14 days after diethylstilbestrol administration. When bacterial inoculation is delayed 21 days after diethylstilbestrol implantation, a decreased incidence of infection is observed even though hydronephrosis is present in all treated animals.

Virulence of the particular bacteria employed is an important factor in evaluating the significance of increased tissue susceptibility to infection. The E. coli used in these experiments did not produce pyelonephritis in normal rats (3), in those acutely depleted of potassium (16), or in rats with the nephrocalcinosis of vitamin D intoxication (17). Pyelography and the surgical procedure employed in the present studies do not appear to enhance the susceptibility of the rat kidney to coliform bacterial infection.

The present studies do not clearly define the mechanism responsible for the increased susceptibility of diethylstilbestrol-treated rat kidneys to infection. The administration of estrogens may produce metabolic alterations responsible for the observed increased susceptibility. No attempt, however, was made to define this possibility in the present study. The histological changes of squamous metaplasia of the transitional epithelium of the bladder and distal and proximal ureters observed in diethylstilbestrol-treated animals may also contribute to enhancement of renal parenchymal infection.

Similar pathological changes have been observed in the genito-urinary tract of male mice treated with estrogen: hydronephrosis and hydroureter, sometimes complicated by spontaneous infection (18); dilatation of the urinary bladder (18-20); and squamous metaplasia of the epithelium of the prostatic urethra and periurethral glands (21). In addition, diethylstilbestrol fed daily to male mink at the rate of $100 \mu \mathrm{g}$ or more produces metaplasia, cornification, and sloughing of the urethral and prostatic epithelium, and/or predisposes mink to spontaneous infection of the urinary tract (22). The extent of metaplasia that develops in the mink depends upon the dose, duration, and continuous administration of diethylstilbestrol. We were unable to correlate the pathological changes observed in the present study with the daily dose of diethylstilbestrol, since the estrogen was ad- ministered in pellets. Nevertheless, the total diethylstilbestrol doses per $100 \mathrm{~g}$ of body weight used in the present study were less than the total doses administered to mink and still produced similar changes including metaplasia of the proximal ureter of the rat.

The hydronephrosis and renal parenchymal infection observed in diethylstilbestrol-treated rats suggest that the physiological and anatomical urinary tract changes of pregnancy may be attributed to "hyperestrogenism." The precise mechanism of this relationship and relevancy to human disease, however, remain to be determined.

\section{Summary}

The administration of diethylstilbestrol to rats with normal urinary tracts results in the development of squamous metaplasia of the transitional epithelium of the bladder and distal and proximal ureters, varying degrees of hydronephrosis, and an increased susceptibility to renal parenchymal infection.

Hematogenous inoculation of Escherichia coli resulted in typical wedge-shaped abscesses in the kidneys of diethylstilbestrol-treated rats. Although renal parenchymal infection did not occur in diethylstilbestrol-treated male rats unless hydronephrosis was present, not all hydronephrotic animals became infected. Susceptibility of the male rat kidney is greatest when the bacteria are inoculated 14 days after diethylstilbestrol administration. A decreased incidence of infection is observed when bacterial inoculation is delayed until 21 days after diethylstilbestrol implantation.

These findings may have some bearing on the increased frequency of pyelonephritis during human pregnancy.

\section{Acknowledgment}

We gratefully acknowledge the technical assistance of Miss Ellen Cooper.

\section{References}

1. Rocha, H., L. B. Guze, and P. B. Beeson. Experimental pyelonephritis. V. Susceptibility of rats to hematogenous pyelonephritis following chemical injury of the kidneys. Yale J. Biol. Med. 1959, 32, 120 .

2. Braude, A. I., A. P. Shapiro, and J. Siemienski. Hematogenous pyelonephritis in rats. I. Its patho- 
genesis when produced by a simple new method. J. clin. Invest. 1955, 34, 1489.

3. Guze, L. B., and P. B. Beeson. Experimental pyelonephritis. I. Effect of ureteral ligation on the course of bacterial infection in the kidney of the rat. J. exp. Med. 1956, 104, 803.

4. Rocha, H., L. B. Guze, L. R. Freedman, and P. B. Beeson. Experimental pyelonephritis. III. The influence of localized injury in different parts of the kidney on susceptibility to bacillary infection. Yale J. Biol. Med. 1958, 30, 341.

5. Beeson, P. B. Factors in the pathogenesis of pyelonephritis. Yale J. Biol. Med. 1955, 28, 81.

6. Hofbauer, J. Contribution to the etiology of pyelitis of pregnancy. Bull. Johns Hopk. Hosp. 1928, 42, 118.

7. Kleeman, C. R., W. L. Hewitt, and L. B. Guze. Pyelonephritis. Medicine (Baltimore) 1960, 39, 3.

8. Kass, E. H. Bacteriuria and pyelonephritis of pregnancy. Arch. intern. Med. 1960, 105, 194.

9. Kass, E. H. Role of asymptomatic bacteriuria in pathogenesis of pyelonephritis in Henry Ford Hospital International Symposium. The Biology of Pyelonephritis, E. H. Kass and E. L. Quinn, Eds. Boston, Little Brown, 1960, p. 399.

10. Kaitz, A. L., and E. W. Hodder. Bacteriuria and pyelonephritis of pregnancy. A prospective study of 616 pregnant women. New Engl. J. Med. 1961, 265, 667.

11. Turck, M., B. S. Goffe, and R. G. Petersdorf. Bacteriuria of pregnancy. Relation to socioeconomic factors. New Engl. J. Med. 1962, 266, 857.

12. Hundley, J. M., Jr., I. A. Siegel, F. W. Hachtel, and J. C. Dumler. Some physiological and pathological observations on the urinary tract during pregnancy. Surg. Gynec. Obstet. 1938, 66, 360.
13. Baker, E. C., and J. S. Lewis, Jr. Comparison of the urinary tract in pregnancy and pelvic tumors. J. Amer. med. Ass. 1935, 104, 812.

14. Traut, H. F., and C. M. McLane. Physiological changes in the ureter associated with pregnancy. Surg. Gynec. Obstet. 1936, 62, 65.

15. Venning, E. H. Adrenal function in pregnancy. Endocrinology 1946, 39, 203.

16. Carone, F. A., M. Kashgarian, and F. H. Epstein. Effect of acute potassium deficiency on susceptibility to infection with particular reference to the kidney. Yale J. Biol. Med. 1959, 32, 100.

17. Freedman, L. R., and P. B. Beeson. Experimental pyelonephritis. VIII. The effect of acidifying agents on susceptibility to infection. Yale J. Biol. Med. 1961, 33, 318.

18. Gardner, W. U. Pelvic changes occurring in male mice receiving large amounts of folliculin benzoate. Proc. Soc. exp. Biol. (N. Y.) 1935, 33, 104.

19. Hasch, R., M. D. Overholser, and L. J. Wells. Effects of oestrogen and androgen injections on reproductive organs in male rats and mice. J. Endocr. 1939, 1, 261.

20. Weller, D., M. D. Overholser, and W. D. Nelson. The effect of estrin on the prostate gland of the albino rat and mouse. Anat. Rec. 1936, 65, 149.

21. Burrows, H. Pathological conditions induced by oestrogenic compounds in the coagulating gland and prostate of the mouse. Amer. J. Cancer 1935, 23, 490.

22. Lauerman, L. H., Jr., and D. T. Berman. Urinary tract infection in mink. II. Diethylstilbestrol as a predisposing factor. Amer. J. vet. Res. 1962, 23, 1097. 